\title{
Optimizing lighting design for hospital wards by defining user zones
}

\author{
N. Thuesen ${ }^{1}$, L. Stidsen ${ }^{2}$, P. H. Kirkegaard ${ }^{2}$, H. Harder ${ }^{1}$ \\ \& V. Suenson ${ }^{1}$ \\ ${ }^{I}$ Department of Architecture, Design and Media Technology, \\ Aalborg University, Denmark \\ ${ }^{2}$ Department of Civil Engineering, Aalborg University, Denmark
}

\begin{abstract}
When studying standards and recommendations for lighting in hospital environments, they often suggest a uniform light distribution to facilitate the needs of the staff. At the same time, the standards recommend a lighting design which supports the patients' feeling of a homely and pleasant atmosphere, however, they also point out that the light should not disrupt the patients' wellbeing. These two approaches are not necessarily consistent because the right quality and quantity of light in wards is highly dependent on the functionality of the space and the desired and expected lighting atmosphere of the space as well as a comparison of lighting design in private and public settings which are often not similar. The purpose of this article is therefore to present an approach dividing the hospital ward in 3 user zones for patients, staff and visitors. The main user of the zone should be in control of the light scenario. Thereby leading to a refining of the lighting design, so it has the ability to support the different users' activities and behavior on the ward.

By using RFID tracking and manual observations, we have analyzed and evaluated the ward functionality as well as the working environment for the staff. The method creates a better understanding of the ward by mapping the flow of the staff and related work situations, which thereby makes is possible to create zones within the space. These zones can be used as guidelines for lighting design with the staff assignments in mind.
\end{abstract}

Keywords: hospital lighting design, behavior mapping tools and methods, RFID tracking, manual observations, zoning of space. 


\section{Introduction}

Lighting plays an important role in the perception of space and atmosphere (Böhme [1], Jörgensen et al. [2]). Light quality is therefore a key element in creating pleasurable and inspiring environments for living, working and recreation.

Hospital design challenges many aspects of architecture and lighting due to the complexity of the space (Loe [3]). The ward has, unlike many other forms of spaces, very different user preferences and needs for light. It is therefore difficult to define pleasurable lighting conditions in this kind of multifunctional space (Ulrich and Zimring [4], McClughan et al. [5], Knez and Enmarker [6], Stidsen et al. [7]). The aim of this article is therefore to investigate how the space of the ward is used and how it can be defined as zones focusing on the different users' needs and preferences.

The tools and methods, which can be used for analysis and evaluation of the ward as a space of high functionality with different users, is going to be the main focus in this paper and the analysis will especially be looking at the staff as a case. The evaluation is based on the theory of Stidsen et al. [8] and Ulrich and Zimring [4].

The main focus of the paper is the staffs' working area, and their use of space and need for light. It discusses the possibilities of dividing the space into zones with different light settings according to the use of space. The results of this paper will be a part of the pre-studies used in the design process of a light installation at a hospital ward at the Department of Orthopedic Surgery at Odense University Hospital, Denmark. The studies will evaluate the presented zoning introduced in this paper and the method used to define zones through tracking and observation of staff.

\section{Lighting in hospital design}

The hospital ward is a 24-hour, seven days a week, working environment with different working conditions and patterns. In Denmark, the daylight conditions available in a room are changing throughout the year and depending on seasons. Almost all year round, the length of a working day is extended by supporting the daylight with artificial light, which thereby becomes a central element of everyday life at the hospital (Forster [9]).

Standards of light installations at hospitals are defined to ensure lighting that satisfies the need for visual assignments of the space. The guidelines do not give specific advice about placement of light but talk about the patients' and staffs' preferences of light. "Patients have few visual tasks, but need lighting design that makes as pleasing surroundings as possible. The staff must have adequate lighting to perform their visually demanding work" (Dansk Standard 703 [10]).

Attempts to save energy by underlighting are therefore a false economy, as without sufficient light, errors and mistakes increases, whereas overlighting creates a higher energy use than necessary (Ulrich [4]). 
Previous research has revealed that the use of artificial lighting occurs to a much greater extent in the hospital environment than in normal commercial and industrial premises. The inconsistency of natural light often results in electric lighting being left switched on also when the light is not needed (Forster [9]).

Therefore, the understanding of the functions of the wards, the users' needs and expectations for lighting is crucial and important in achieving a pleasurable light atmosphere (Stidsen et al. [11]).

\subsection{The design approach}

The theories of the design approach are based on a model presented by Stidsen (Stidsen [8]). The model clarifies the parameters which are interplaying in the experience of light atmosphere in wards. "The purpose of the model is to display the parameters influencing the judgments of the lighting design and form the basis parameters of a pleasant hospitalization" (Stidsen [8, p.9]). The model introduces different elements that influence the atmosphere, the main elements being;

- Users

- Time

- Space

- Light source

The light source can be divided into daylight and artificial light. Daylight is mostly affected by the architectural layout of the space and the placement of windows, whereas artificial lighting, on the other hand, is meant to support the daylight. Time is affecting the daylight but time of day and season of year also influence the perception of light and thereby, also affects the need for light. The users can be divided into different groups as the patients, the staff (doctors, nurses, cleaning staff), and the visitors (family, friends), which all make the model specific for hospital wards.

The light atmosphere of the ward is crucial for the patients' experience of wellbeing, but there is a huge different in the requirements and expectations for light because of the different user groups [12]. The staff has to perform high demanding visual task such as examination and communication with the patients whereas the ward for the patients is not a work space but a space for rehabilitation and recuperation. The visitors are only using the space for shorter time periods where the patient is in focus (Stidsen [8]). This problematic is also described in Dansk standart 703 "The requirements for lighting in hospitals are quite complicated because two different needs must be met, being both patients and staff' (Dansk Standard [10]).

It is our experience that most ward lighting is satisfying or focusing on the staffs' needs for light, because of the uniform light distribution mounted to the ceiling. By zoning the ward and thereby defining "staff zone", "patient zone" and "visitor zone" it gives the lighting designers the opportunity to create a light scenario designed for needs, preferences and expectations for all users of the ward [13]. This article presents the study of the definition of the staff zone and 


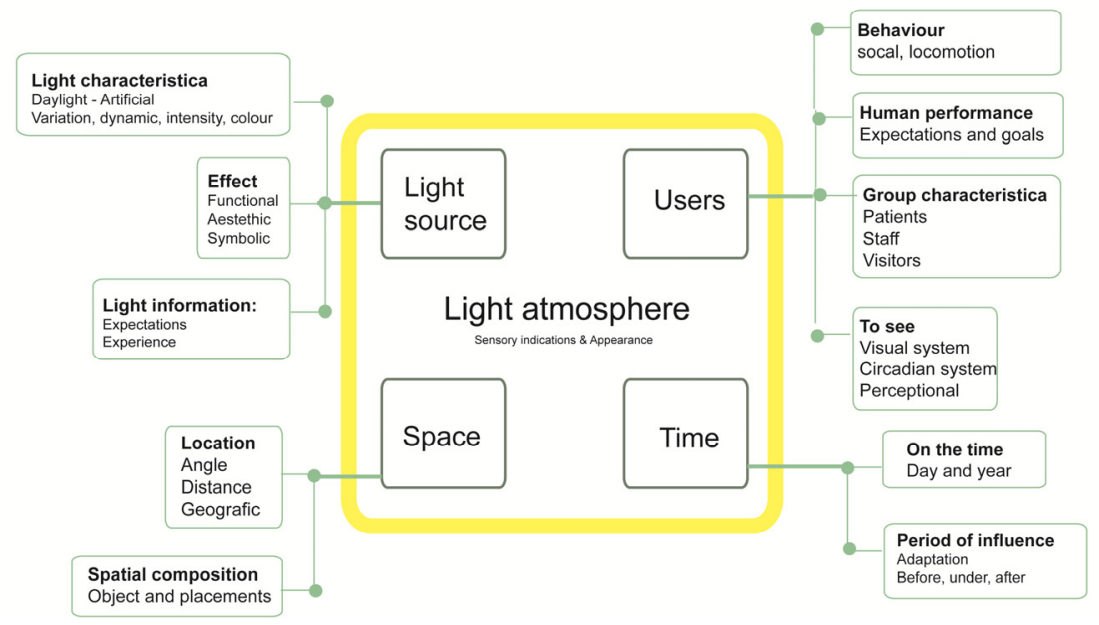

Figure 1: The model of parameters in light atmosphere in wards.

their need for light, thereby not saying that the other users play a less important role in creating a good lighting atmosphere. The focus is concentrated on the staff to clarify a part of the parameters that play an important role in creating a good lighting atmosphere in wards for all users.

\subsection{Methods of analyzing space}

How the artificial lighting could support the functionality of the ward and the functions of the ward is important and it needs to be defined exactly even though the ward is a small space. There are many different ways to gather information concerning behavior flow of work situations (Suenson et al. [14], Millonig and Gartner [15] and Hillier and Hanson [16]). The selection of tools has to be wellgrounded to give the right results. Unobtrusive observations avoid participants feeling under observation which can change the way they act which thereby can blur the results. Unobtrusive observations are therefore preferred because it avoids the risk of such "observer effects" (Millonig and Gartner [15]).

One of the methods to clarify the use of spaces is questionnaire surveys. Questionnaire surveys can provide comparatively large samples, and allow the collection and analysis of data within a short amount of time. But the human behavior can hardly be mapped and can only be interpreted by verbal structures.

Another category of surveys is direct observation, such as mapping or tracking. These surveys can be done in many different ways, the simplest one being manual observations that are recorded by notes and drawings. Monitoring by video is another way to analyze and interpret human behavior (Millonig and 
Gartner [15]). The limitations by using video are the view of space for observation which can be limited. This limitation is not present because the ward is a small space, but observations by video cannot be used in wards because of the privacy of the patients that need to be respected.

A new developed tool to gather information about human behavior is the digitally based localization technologies. An example of this could be satellite based technology such as GPS (Global Positioning System) which can gather data within a very large study area. For indoor observations, the GPS system is insufficient as data basis because of the lack of signal between receivers and satellites (Millonig and Schechtner [17] and Suenson et al. [14]).

An alternative to the GPS system is the RFID (Radio Frequency Identification) technology. The RFID system use radio waves to identify people and objects instead of satellites, which makes it possible to be used indoor and which is not possible with GPS. RFID is still a new developed tool for tracking indoor behavior and therefore, the data collected by this technology can be more complicated to gather and interpret than GPS at the point of writing Millonig and Gartner [15] and Suenson et al. [14]).

The study of functions and use of space can be improved by combining different techniques. The combinations of manual observation and digital tracking with RFID clarify both the flow in space and the functions related to the space. The combinations of the tools are therefore picked for further studies of the staff behavior in the space.

The staffs' use of the ward space is investigated by RFID-technology of tracking and visual observations. This method is chosen because of its possibilities to make digital recordings indoor, combined with manual observation where the work situations are recorded.

\section{Analyzing the work flow of the ward}

The selected study case is a ward at the orthopedically department at Odense University Hospital, Denmark made in October 2010. It is a type of ward where the staff are often summoned to help patients in and out of the bed or in other ways supervising the patients. The interior design of the ward is fixed and cannot be changed and the layout of the ward can be seen in figure 2 .

The RFID-technology is based on receivers (lommys) and senders (tags). A signal is sent out every 30 seconds from the tag and when the lommy is within the radius of the signal a registration is made. When the lommy is without the radius of the tag, it is also registered. The radius of the Tags can be calibrated to fit different setups (Simonsen [18]). An experimental setup of the tags and radius of signal is made as illustrated in figure 3. All the members of the staff, having contact to the patients inside the ward, are given a lommy from nr. 1 to 5 .

The setup indicates the time when the staff is entering or leaving the ward and if they are situated near bed 1 or 2 . The investigation thereby indicates the staffs work situation at the wards length and if the staff is situated near the hospital beds. The tracking is supplemented by visual observations for a whole day together with a day of hospitalization as a patient, where the different work 
related assignments are recorded. The time scope of the investigation with RFID is from 10.30 to 18.00 .

The study shows that the staff has a high frequency of short periods of time inside the ward, whereas the frequency of longer periods situated inside the ward is smaller. The results can be seen in table 1 . The observations indicated that the staff in the long periods is dealing with mobilization and training of the patient while short periods in the ward mainly are concentrated around calls from the patients and food serving. In the period of the investigation, five different members of the staff were entering the ward.

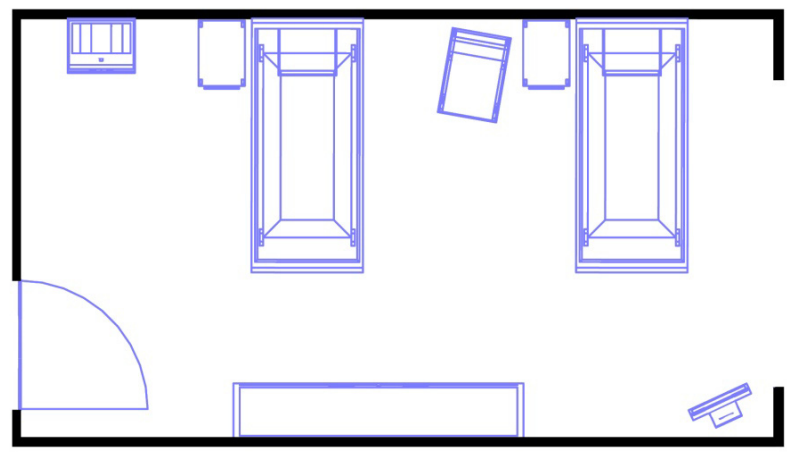

Figure 2: $\quad$ Layout of the ward.

Table 1: Table showing the result of the RFID-tracking of the staff.

\begin{tabular}{|c|c|c|c|c|c|}
\hline $\begin{array}{c}\text { Lommy } \\
\text { nr. }\end{array}$ & $\begin{array}{c}\text { Entering } \\
\text { ward }\end{array}$ & $\begin{array}{c}\text { Time at } \\
\text { bed nr. 1 }\end{array}$ & $\begin{array}{c}\text { Time at } \\
\text { bed nr. 2 }\end{array}$ & $\begin{array}{c}\text { Leaving } \\
\text { ward }\end{array}$ & $\begin{array}{c}\text { Time inside } \\
\text { ward }\end{array}$ \\
\hline nr. 1 & 11.00 & $3 \mathrm{~min}$ & & 11.03 & $3 \mathrm{~min}$ \\
\hline nr. 1 & 11.04 & $1 \mathrm{~min}$ & & 11.05 & $1 \mathrm{~min}$ \\
\hline nr. 2 & 12.08 & $2 \mathrm{~min}$ & & 12.10 & $2 \mathrm{~min}$ \\
\hline nr. 3 & 12.10 & & $2 \mathrm{~min}$ & 12.12 & $2 \mathrm{~min}$ \\
\hline nr. 3 & 12.24 & $1 \mathrm{~min}$ & $1 \mathrm{~min}$ & 12.26 & $2 \mathrm{~min}$ \\
\hline nr. 2 & 14.38 & & $3 \mathrm{~min}$ & 14.41 & $3 \mathrm{~min}$ \\
\hline nr. 1 & 14.38 & & $2 \mathrm{~min}$ & 14.40 & $2 \mathrm{~min}$ \\
\hline nr. 4 & 16.36 & & $5 \mathrm{~min}$ & 16.41 & $5 \mathrm{~min}$ \\
\hline nr. 5 & 16.47 & $8 \mathrm{~min}$ & $14 \mathrm{~min}$ & 17.09 & $22 \mathrm{~min}$ \\
\hline nr. 5 & 17.39 & & $2 \mathrm{~min}$ & 17.41 & $2 \mathrm{~min}$ \\
\hline
\end{tabular}




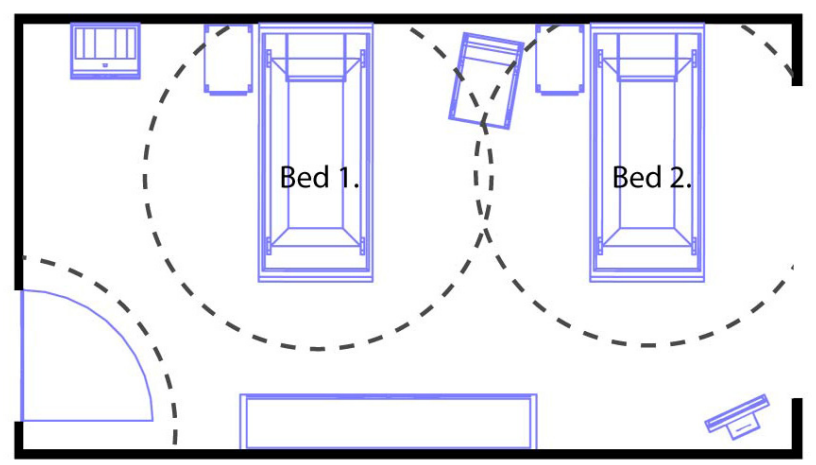

Figure 3: The placement of tags in the ward and their radius.

\section{Zoning of space}

Dividing the ward in zones can be done to visualize the functional differences of the space to benefit the different users' needs and preferences. The zoning makes it possible to design adiversity in the light setting and still fulfill the requirements concerning light and visual tasks for all users. The zones can therefore be used as guidelines in the following design of the lighting (Malkin [19]).
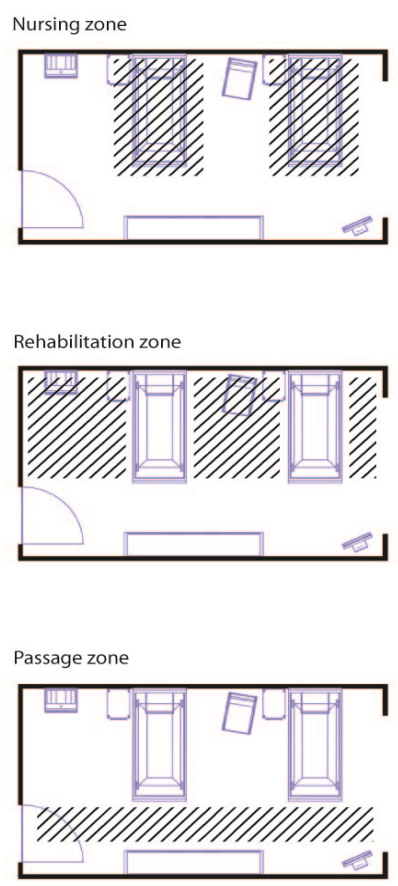

Figure 4: The different work and visitor related zones inside the ward. 
The combination of tracking and observation makes it possible to divide the ward into different zones. The zones are defined from an understanding of the space, which makes it possible to modify the light sources according to the functionality. The zones are a simplification of the complexity of the ward, and there will therefore be work situations that do not fit these categories. The zones are illustrated in figure 4.

The high frequencies of short stays strengthen the problems of lighting being left turned on of the staff when leaving the room again. This problem can lead to overlighting of the ward, and at worst be uncomfortable for the patients. The problem is also based in the immobility of the patients, which makes them unable to turn off the light themselves. Fagerhults [20]

Greater divisions of lighting control are therefore important for energy savings, the work of the staff and for the wellbeing of the patients. A division of light control can be a solution to this problem but need further examination. For further information about studies in this area see the article "Patients light preferences in hospital wards - related to light atmosphere in Danish homes" by L. Stidsen, H. S. Bjerrum, N. Thuesen, P. H. Kirkegaard, A. M. Fisker.

\subsection{Lighting of the ward in zones}

The division of zones illustrates that the lighting do not need to be uniform but can vary according to the quantity and quality of light preferred or needed in each zone. It indicates that the high demanding visual tasks are situated near the beds or in the perimeter of the beds. Difficult visual task demands high intensity of light depending on the task and the guidelines for treatments and examinations of patients states a minimum of 300 lux (Lang [21] and Danish Standards [10]) states a need for at least 500 lux.

The high intensity of light should therefore be concentrated in the nursing zone and at the perimeter of the bed. In the rehabilitation zone, lighting between 200 and 300 lux is estimated as sufficient to solve the visual task for the staff and patients.

The passage zone does not need the same amount of lux seen from the functionality of the staff point of view. The stated efficiency of lighting in such areas is recommended to be around 50 to 100 lux as the area does not contain any high demanding visual tasks (Lang [21]). In situations where cleaning of the whole ward is necessary, a minimum quantity of light on 200 lux is required and it is therefore also important that it can be achieved. ".... in addition to a standard illumination of $50 \mathrm{lux}$, it is possible to achieve an illumination of 200 lux for cleaning, ward rounds, etc., if conditions require it" (Dansk Standard [10]).

The divisions of zones are made in the horizontal plan, but a dividing of zones should also be done in vertical plan to fully unfold the potential of zoning. A vertical division of zones could be done by investigating the level in which functions are executed.

The distribution of lighting in terms of lux levels are placed according to the zones as can be seen in figure 5 . 


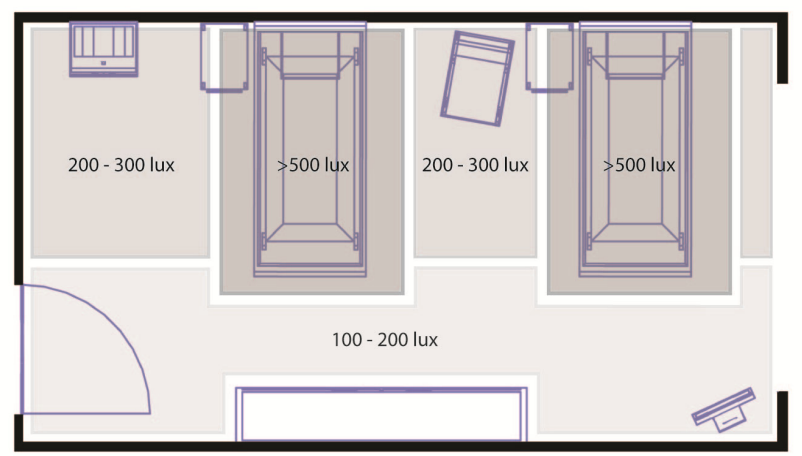

Figure 5: The lux levels needed according to the use of the space.

\section{Conclusion}

The goal of this paper was to investigate methods to analyze space with the aim of zoning the ward and thereby creating guidelines about lighting of the ward. The studies indicate that RFID tracking of staff combined with observations of the staffs work and time at the ward clarify the working functionality of the space, and thereby illustrates that from the staffs' point of view, the ward can be divided into different zones. From zoning the ward, lighting can be more specified and thereby improve preferences, needs and furthermore reduce energy use on lighting because it becomes possible to illustrate areas of high and low visual assignments. The highest demand for light is in the areas at the hospital bed and in the perimeter next to the bed, and the lowest in the passage zones in front of the door.

The studies in this paper are focusing on the method and design parameters for lighting. The tools used for analyzing the space produce quantitative data for interpretation and because of the small time scope, the data is only giving an indication on how the ward is used. For more reliable results, tracking and observations need to be made for a longer period of time with a higher level of setup. Further studies should therefore be done in the future to strengthen the results emphasized in the investigations.

\section{References}

[1] Böhme, G., Atmosphere as the Fundamental Concept of a New Aesthetics, Sage, 1993.

[2] Jörgensen, K.N., Römma, V. \& Rundmo, T., “Associations between ward atmosphere, patient satisfaction and outcome." Journal of Psychiatric and mental Health Nursing, vol. 16, pp. 113-120, 2009. 
[3] Loe, D. \& Perry, M., Hospital in the best light: an introduction to hospital lighting, BRE, United Kingdom, 2000.

[4] Ulrich, R., Zimring, C. The Role of the Physical Environment in the Hospital of the 21st Century: A Once-in-a-Lifetime Opportunity, pp. 12, 2004.

[5] McClughan, C.L.B., Aspinall, P.A. \& Webb, R.S., "The impact of lighting on mood", Lighting Research, 1999.

[6] Knez, I. \& Enmarker, I., "Effects of Office Lighting on mood and Cognitive Performance and a Gender Effect on Work-xRelated Judgement" pp. 553. Technology, vol. 7, no. 31, pp. 88, 1998.

[7] Stidsen, L., Kirkegaard, P.H., Fisker, A.M. \& Jensen, R., "Lighting Quality in Wards - Design Parameters for a Pleasurable Light Atmosphere.", Adjunkt proceedings. Experiencing Light 2009, International conference on the Effect of Light on Wellbeing, eds. Y.A. de Kort W., W.A. IJsselsteijn, I.M.L.C. Vogels, M.P.J. Aarts, A.D. Tenner \& K.C.H.J. Smolders, pp. 31, 2009.

[8] Stidsen, L., Kirkegaard, P. H., Fisker, A. M., Lighting quality in hospital wards; Design parameters for a pleasurable light atmosphere: Aalborg University pp. 19-32, 2009.

[9] Forster, R., Efficient hospital lighting, Technology \& Services, Business Briefing: Hospital Engineering \& Facilities Management, pp. 1-4, 2005.

[10] Dansk Standard 703 - Retningslinjer for kunstig belysning i sygehuse (Directions for lighiting in hospitals) 1983, Dansk Standardiseringsråd.

[11] Stidsen, L., Kirkegaard, P.H. \& Fisker, A.M., "Design proposal for pleasurable light atmosphere in hospital wards", Knemesi, Italy, pp. 366, 2010.

[12] Malnar, J.M. \& Vodvarka, F., "The light fantastic" in Sensory Design University of Minnasota Press, Minnasota, pp. 199, 2004.

[13] Stidsen, L., Kirkegaard, P.H. \& Fisker, A.M., "Design paramteres for evaluating light settings and light atmosphere in hospital wards", 2nd CIE Expert Symposium on Appearance, When Appearance meets LightingIbeBiv, Gent, pp. 136, 2010.

[14] Suenson. V., Harder, H., Tradisauskas, N., Simonsen, A. K., Knudstrup, M. Walking the library, Aalborg University Vesterkopi, pp. 20 - 462010.

[15] Millonig, A., Gartner, G., Exploring Human Spatio-Temporal Behaviour Patterns, The Cartography and Geographic Information Society (CaGIS), pp. $1-12,2008$.

[16] Hillier. B., Hanson, J., The social logic of space, Cambridge University press, Cambridge, 1984

[17] Millonig, A., Schechtner, K., Developing Landmark-based Pedestrian Navigation Systems, Proceedings of the 8th International IEEE Conference on Intelligent Transportation Systems Vienna, Austria, pp. 197 - 201, 2005

[18] Simonsen, A. K., Indendørs sporing vha. RFID-teknologi, Aalborg University, pp. 17- 29, 2010

[19] Malkin. J., A visual Reference for Evidence-Based Design, The center for health design, pp. 7.28-7.41, 2008 
[20] Fagerhults, B. The Importance of Good Lighting, Technology \& Services, Business Briefing: Hospital Engineering \& Facilities Management 2003

[21] Lang. S., Good Lighting for Healthcare Buildings, Technology \& Services, Business Briefing: Hospital Engineering \& Facilities Management, pp. 1-4, 2003. 